\title{
Iron sources for Haemophilus ducreyi
}

\author{
B. C. LEE
}

Department of Microbiology and Infectious Diseases and Division of Infectious Diseases, Department of Medicine, The University of Calgary, 3330 Hospital Drive, NW, Calgary, Alberta, Canada T2N 4N1

\begin{abstract}
Summary. The ability of various haem- and non-haem-iron-containing compounds to support the growth of iron-limited cultures of Haemophilus ducreyi was assessed in a plate bioassay. Only haemin or the haem-containing proteins, bovine haemoglobin, human haemoglobin and bovine catalase, but not equine cytochrome $C_{111}$, were capable of serving as the sole exogenous iron source. Complexes of haptoglobin-haemoglobin and haem-serum albumin retained the ability to function as iron substrates. In contrast, no growth was observed with $\mathrm{FeCl}_{3}$, human lactoferrin and human transferrin. Siderophore production was not detected with a universal chemical assay. Outer-membrane-protein profiles derived from iron-starved cultures revealed four iron-regulated polypeptides of $65,50,45.5$ and $40.5 \mathrm{Kda}$. These results indicate that haem can supply the requisite iron for growth of $\boldsymbol{H}$. ducreyi.
\end{abstract}

\section{Introduction}

The requirement for iron is a ubiquitous phenomenon of living cells. ${ }^{1,2}$ A plethora of experimental evidence supports the contention that the ability of a bacterial pathogen to acquire iron governs its pathogenic potential and represents an essential component of its virulence repertoire. ${ }^{1,2}$ However, the human body affords a hostile, iron-restrictive environment to a bacterial invader. Iron is sequestered in haemcontaining proteins such as haemoglobin or myoglobin, and in ferritin or complexed to the iron-binding glycoproteins, lactoferrin (Lf) and transferrin (Tf), which in aggregate limits the available free iron to levels insufficient to support microbial growth. ${ }^{1,2}$

In response, bacteria have developed sophisticated high-affinity systems to scavenge this essential element from their external environment. One such method involves the elaboration of low molecular weight ironchelators, called siderophores, that solubilise and bind iron prior to its internalisation. ${ }^{1-3}$

Recently, a receptor-mediated mechanism for the uptake of iron from $L f$ and $T f$ has been described in Haemophilus influenzae ${ }^{4,5}$ and in the pathogenic Neisseria spp. ${ }^{6,7}$ The Lf receptors (LfR), and to a lesser extent the $T f$ receptors (TfR), of these organisms exhibit similarities in their molecular weights and in their ligand and functional specificities, implying an interspecies structural and functional conservation of these receptors.

$H$. ducreyi, a fastidious gram-negative cocco-bacillus causes chancroid, a sexually transmitted genital ulcer disease. ${ }^{8}$ Although this organism also possesses an obligate requirement for haem,, 90 nothing is known about its iron acquisition mechanisms.
The recent epidemiological demonstration that genital ulcer disease is an independent risk factor for the acquisition of HIV ${ }^{11}$ coupled with the re-emergence of chancroid as a significant sexually transmitted disease (STD) in North America, ${ }^{12}$ has spurred renewed interest in this pathogen. However, studies on the metabolism of $H$. ducreyi have been hampered, in part, by the dearth of suitable in-vitro broth culture media. ${ }^{9,10,13}$

Therefore, this investigation was conducted initially to develop a plate bioassay to circumvent the impediment imposed by the lack of broth media to support the growth of $\boldsymbol{H}$. ducreyi. The development of this bioassay system permitted the identification of physiological iron-containing compounds that might be anticipated to furnish the requisite iron for growth in $H$. ducreyi, in order to provide an initial understanding of the mechanisms for iron uptake in this organism and to compare them with the mechanisms in $H$. influenzae.

\section{Materials and methods}

\section{Bacterial strains}

$H$. ducreyi strains, kindly provided by $\mathrm{R}$. Brunham (University of Manitoba, Winnipeg, Canada) (table I), were maintained in skimmed-milk stock cultures at $-70^{\circ} \mathrm{C} . N$. meningitidis BI6B6 was a Group B:2a serotyping strain. ${ }^{7}$ Streptococcus pneumoniae ATCC27336 and S. pyogenes ATCC21547 were used as positive controls in the haemolysin assay. Pseudomonas aeruginosa $\mathrm{PAO}^{14}$ was provided by L. E. Bryan (University of Calgary, Canada). When needed, strains were cultured on chocolate agar (CA)-GC Medium Base (Difco Laboratories, Detroit, MI, USA) 
Table I. $H$. ducreyi strains

\begin{tabular}{llc}
\hline Strain no. & \multicolumn{1}{c}{ Source } & $\begin{array}{c}\beta \text {-Lactamase } \\
\text { production }\end{array}$ \\
\hline HD1 & Sweden & - \\
CH28 & Thailand & + \\
35000 & Winnipeg, Manitoba, Canada & - \\
CIP542 & Institut Pasteur, Paris, France & - \\
V1157 & Seattle, Washington & + \\
BG411 & Nairobi, Kenya & + \\
$36-F-2$ & Paris, France & - \\
E1673 & Sweden & - \\
& & \\
\hline
\end{tabular}

supplemented with bovine haemoglobin (Difco) $1 \%$ and CVA Enrichment (Gibco Canada Inc., Burlington, ON, Canada) $1 \%$-incubated at $35^{\circ} \mathrm{C}$ in air + $\mathrm{CO}_{2} 5 \%$ with high humidity.

Growth on CA was identified as $H$. ducreyi by the non-mucoid, yellow-grey appearance and the cohesive nature of the colonies which enabled them to be pushed intact across the agar surface. Biochemically, they were oxidase-positive and catalase-, urease-, and ornithine decarboxylase-negative; they did not produce indole or $\mathrm{H}_{2} \mathrm{~S}$, and did not ferment glucose, sucrose, lactose, mannitol or xylose. Microscopy showed that all organisms were small, pleomorphic, gram-negative rods.

\section{Iron-containing compounds}

Iron-containing compounds were purchased from Sigma Chemical Co., St Louis, MO, USA. The procedures used to prepare the iron-loaded human lactoferrin (hLf) and human transferrin (hTf) were described previously. ${ }^{7}$ Bovine haemin $(\mathrm{bHm})$, bovine haemoglobin (bHb), human haemoglobin $\mathrm{A}(\mathrm{hHb})$, equine cytochrome $\mathrm{C}_{111}$ and bovine catalase were prepared fresh daily. With the exception of bovine haemin, which was solubilised initially in $0 \cdot 1 \mathrm{~N} \mathrm{NaOH}$, the haem proteins were dissolved in deionised water and sterilised by membrane filtration immediately before use.

\section{Reagents for siderophore detection}

Chrome azurol S (CAS) and hexadecyltrimethylammonium bromide (HDTMA) were purchased from Fluka Chemical Corp., Ronkonkoma, NY, USA. Pipes (free acid), the salts comprising the MM9 growth medium ${ }^{15}$ and $\mathrm{FeCl}_{3} \cdot 6 \mathrm{H}_{2} \mathrm{O}$ were obtained from Sigma.

\section{Media}

The semi-defined agar medium (DM) used comprised GC medium base (Difco) with glucose (Sigma) $0 \cdot 1 \%$, L-glutamine (Sigma) $0.01 \%$ and L-cysteine $\mathrm{HCl}$ (Sigma) 0.025\%.

\section{Serum proteins}

Human serum albumin (hSA) and human haptoglobin (hHp), which comprised a mixture of $1: 1,2: 1$ and 2:2 electrophoretic variants, ${ }^{16}$ were obtained from Sigma. Complexes of haem with hSA and of hHb with $\mathrm{hHp}$ were prepared as previously described. ${ }^{17}$ The carrier proteins were saturated at $50 \%$ capacity, assuming a 1:1 stoichiometry of binding of haem to hSA and of hHb to Hp. ${ }^{18}$

\section{Isolation and characterisation of outer-membrane proteins (OMPs)}

OMPs were isolated by the method of Hancock and Nikaido, ${ }^{19}$ as modified by Godfrey et al. ${ }^{20}$ from organisms grown under the following conditions: iron replete [CA supplemented with CVA $1 \%$ ], haeminrich [DM containing $200 \mu \mathrm{M}$ ethylenediamine $\mathrm{Di}-(O-$ hydroxyphenylacetic acid) (EDDA) and $200 \mu \mathrm{M}$ bovine haemin], iron- and haemin-limiting [DM containing $38 \mu \mathrm{M}$ bovine haemin and $200 \mu \mathrm{M}$ EDDA] and haemin-restrictive [DM with the addition of $38 \mu \mathrm{M}$ bovine haemin]. Protein concentration was determined by the method of Lowry ${ }^{21}$ with bovine serum albumin as a standard. The proteins were separated by discontinuous sodium dodecyl sulphate-polyacrylamide gel electrophoresis (SDS-PAGE) in $1.5-\mathrm{mm}$ thick slab gels with stacking $5 \% \mathrm{w} / \mathrm{v}$ and gradient acrylamide (BioRad Laboratories, Richmond, CA, USA) $8-12 \%$ separating gels with bisacrylamide (BioRad) $0.8 \%$, and the buffer system of Laemmli. ${ }^{22}$ Gels were loaded with $50 \mu \mathrm{g}$ of protein per lane. The resultant gels were stained with silver. ${ }^{23}$ Molecular weights were determined with known proteins as standards.

$\mathrm{Hb}-\mathrm{Hp}$ complexes were analysed by non-denaturing PAGE, a protocol in which SDS was eliminated from the sample gel and running buffers and the sample was not subjected to thermal denaturation before electrophoresis. After reduction of the gel in methanol $50 \%,{ }^{24}$ haemoglobin and $\mathrm{Hb}-\mathrm{Hp}$ complexes were stained for peroxidase activity by the benzidine stain described by Moore. ${ }^{25}$

\section{Plate assays}

Because $H$. ducreyi exhibits intercellular adherence, uniform suspensions of this organism are difficult to achieve. This intrinsic character precluded the adaptation of traditional plate assays, in which organisms are incorporated in molten agar, to evaluate the availability of iron from haem and non-haem proteins. Therefore, to determine the minimum haemin requirement necessary to support growth, organisms derived from a 24-h culture on CA were suspended in $50 \mathrm{~mm}$ sodium phosphate buffer, $\mathrm{pH} 7 \cdot 0$. The optical density was adjusted to a $0.5 \mathrm{McF}$ arland standard (approximately $10^{8} \mathrm{cfu} / \mathrm{ml}$ ). By means of a Steer's replicator, which delivered approximately $10^{5} \mathrm{cfu}$, organisms 
were inoculated on to DM containing serial two-fold dilutions of bovine haemin. Plates were incubated at $35^{\circ} \mathrm{C}$ in air $+\mathrm{CO}_{2} 5 \%$. The presence or absence of growth was assessed with a hand lens after incubation for 24,48 and $72 \mathrm{~h}$. Only plates on which there was visible growth yielded viable organisms on subculture to CA.

A similar procedure was used to assess the ability of the various iron-containing compounds to support growth. Organisms were sequentially passaged once on CA, DM plus $38 \mu \mathrm{M}$ bovine haemin, and DM plus $38 \mu \mathrm{M}$ bovine haemin and $200 \mu \mathrm{M}$ EDDA. The incorporation of EDDA, a potent iron chelator, ${ }^{7}$ into the DM complexed any available free iron in the medium. A preliminary series of titrations indicated that this concentration of EDDA was sufficient to impose iron limitation, as reflected in the $\mathrm{Tf}$ and $\mathrm{Lf}$ receptor expression of $N$. meningitidis strain B16B6 (see below). Organisms grown under these iron-and haeminrestricted conditions were then inoculated with a Steer's replicator on to similar EDDA-containing plates in which the following iron-containing compounds were individually substituted in lieu of bovine haemin: $9.5 \mu \mathrm{M} \mathrm{bHb}, 50 \mu \mathrm{M} \mathrm{FeCl}_{3}, 250 \mu \mathrm{M} \mathrm{FeCl}_{3}$, $7.5 \mu \mathrm{M}$ hTf, $1 \mu \mathrm{M}$ hLf, $9.5 \mu \mathrm{M}$ catalase, and $38 \mu \mathrm{M}$ cytochrome $\mathrm{C}_{111}$. Because of the haem dependency of $H$. ducreyi, plates containing the non-haem iron compounds, $\mathrm{FeCl}_{3}$, hTf and hLf, were supplemented with the haem precursor, protoporphyrin IX (PPIX), at a concentration of $38 \mu \mathrm{M}$. Human $\mathrm{Hb}$ was added at a final concentration of $38 \mu \mathrm{M} \mathrm{Fe}$, either free or complexed to hHp. Human haemin bound to hSA was added at a final concentration of $38 \mu \mathrm{M}$ Fe. All assays were performed in triplicate.

\section{Detection of siderophore production}

Because the inability of $H$. ducreyi to grow in liquid media precluded the application of conventional bioassays for the detection of siderophores, the chemical method of Schwyn and Neilands ${ }^{15}$ which could be readily adapted for use on agar plates, was used. A further advantage inherent in this method was its universality, which facilitated the detection of structurally novel siderophores that possess functional groups other than hydroxamates or catechols. Organisms rendered iron- and haemin-deficient by sequential passage, as previously described, were inoculated by a Steer's replicator on to DM containing $38 \mu \mathrm{M}$ $\mathrm{bHm}$ and the plates were incubated at $35^{\circ} \mathrm{C}$ in air + $\mathrm{CO}_{2} 5 \%$. Following the appearance of visible growth after incubation for $36-48 \mathrm{~h}$, the plates were overlaid with $20 \mathrm{ml}$ of CAS agar. ${ }^{15}$ Siderophore excretion, as indicated by the presence of orange haloes around the colonies, was assessed with reference to the indicator strains, P. aeruginosa PAO1 and N. meningitidis B16B6, after incubation for 24,48 and $72 \mathrm{~h}$ at $35^{\circ} \mathrm{C}$. All tests were performed in triplicate. This overlay modification was necessary because toxicity of the detergent component, HDTMA, for $\boldsymbol{H}$. ducreyi (data not shown) prevented the use of the original method of direct plating on to CAS agar.

\section{Lf and Tf receptor dot-binding assay}

Organisms and OMP preparations derived from whole cells grown on DM with $38 \mu \mathrm{M}$ haemin and $200 \mu \mathrm{M}$ EDDA were probed for the presence of $\mathrm{Lf}$ and Tf receptor expression as described previously. ${ }^{6} \mathrm{~N}$. meningitidis B16B6 was tested as a positive control.

\section{Haemolysin assay}

To detect the presence of haemolysins, organisms were streaked on to and "stabbed" into modified blood-agar plates consisting of $10 \mathrm{ml}$ of DM with $38 \mu \mathrm{M}$ bovine haemin overlaid with a second $10 \mathrm{ml}$ of DM containing bovine haemin and either defibrinated sRBC $5 \%$ or defibrinated hRBC $5 \%$. Concurrent plates were rendered iron-limiting by the addition of $200 \mu \mathrm{M}$ EDDA. Cultures were incubated at $35^{\circ} \mathrm{C}$ in air $+\mathrm{CO}_{2}$ $5 \%$ or anaerobically at $35^{\circ} \mathrm{C}$ in an Anaerocult (BDH Chemicals Canada Ltd, Edmonton, AB, Canada) system. Haemolytic activity was assessed after 24,48 , 72 and $96 \mathrm{~h}$.

\section{Results}

\section{Haem requirement of $H$. ducreyi}

All the $H$. ducreyi strains exhibited an obligate requirement for haemin; a minimum concentration of $38 \mu \mathrm{M}(25 \mu \mathrm{g} / \mathrm{ml})$ was necessary to initiate growth. The substitution of protoporphyrin IX, the immediate precursor of haem in its biosynthetic pathway, did not support growth.

\section{Plate bioassays to determine the use of iron- containing compounds}

Molar equivalents of haem as $\mathrm{bHm}, \mathrm{bHb}, \mathrm{hHb}$, and catalase supported the growth of all the $H$. ducreyi isolates (table II) with growth detected after incubation for $48 \mathrm{~h}$, but cytochrome $\mathrm{C}_{111}$ did not support growth. Although no qualitative growth differences between cultures on media containing the various defined haem proteins were observed, there was some interstrain heterogeneity in the ability of these compounds to act as the sole iron source. In contrast, no strains were able to obtain the iron required for growth from hTf (fig. 1) or hLf. All the $H$. ducreyi strains assimilated $\mathrm{FeCl}_{3}$ poorly; little or no growth was present even after prolonged incubation ( $>72 \mathrm{~h}$ ) (table II). $N$. meningitidis B16B6 was capable of utilising all of the compounds as the sole exogenous source of iron. 
Table II. Acquisition of haem from various haem-containing proteins

\begin{tabular}{|c|c|c|c|c|c|c|c|c|c|c|}
\hline \multirow{2}{*}{ Strain no. } & \multicolumn{10}{|c|}{ Haem acquired from } \\
\hline & $\mathrm{FeCl}_{3}$ & hLf & hTf & $\mathrm{hHb}$ & $\mathrm{hHb}$ & cytochrome $\mathrm{C}_{111}$ & catalase & bhm & hHb-hHp & $\mathrm{hm}-\mathrm{hSA}$ \\
\hline $\begin{array}{l}\text { N. meningitidis B16B6 } \\
\text { H. ducreyi }\end{array}$ & + & + & + & + & + & + & + & + & + & + \\
\hline HD1 & - & - & - & + & + & - & + & + & + & + \\
\hline CH28 & - & - & - & + & + & - & + & + & + & + \\
\hline 35000 & - & - & - & + & + & - & + & + & + & + \\
\hline CIP542 & - & - & - & + & + & - & + & + & + & + \\
\hline V1157 & - & - & - & + & + & - & + & + & + & + \\
\hline BG411 & - & - & - & + & + & - & + & + & + & + \\
\hline $36-F-2$ & - & - & - & + & + & - & + & + & + & + \\
\hline E1673 & - & - & - & + & + & - & + & + & + & + \\
\hline
\end{tabular}

1

A

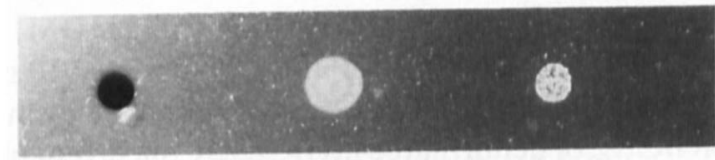

B

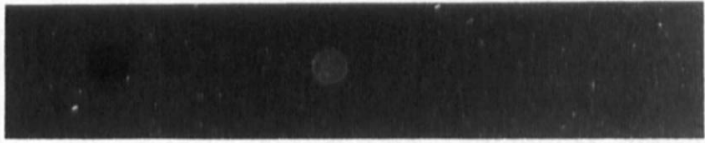

Fig. 1. Growth response of $H$. ducreyi 35000 and $N$. meningitidis B16B6 to hHb and hTf after incubation for $48 \mathrm{~h}$ on iron-limited DM containing (A) $38 \mu \mathrm{M} \mathrm{hHb}$ and (B) $7.5 \mu \mathrm{M}$ of $100 \%$ saturated hTf as the sole iron source. Row 1 , Indian ink reference point; $2, N$. meningitidis $\mathrm{B} 16 \mathrm{~B} 6 ; 3, \mathrm{H}$. ducreyi 35000 .

\section{Effect of serum carrier proteins on growth}

Haem bound to hSA, and hHb bound to hHp, remained suitable iron substrates because the haem was readily available for growth (table II). Nondenaturing PAGE of apo-hHp, free $\mathrm{hHb}$ and mixtures of the two confirmed that the $\mathrm{hHp}$ preparations were capable of binding $\mathrm{hHb}$ (data not shown). The addition of $\mathrm{hHb}$ to $\mathrm{hHp}$ resulted in a retardation of the electrophoretic mobility of both $\mathrm{hHb}$ and $\mathrm{hHp}$, consistent with $\mathrm{hHp}-\mathrm{hHb}$ complex formation.

\section{Analysis of siderophore production}

Siderophore production was not detected in $H$. ducreyi by the modified CAS agar assay. Appropriate reactions were obtained with the positive control strain, $P$. aeruginosa $\mathrm{PAO}$, which elaborates hydroxamate (pyoverdin) ${ }^{26}$ and phenolic (pyochelin) ${ }^{27}$ siderophores, and with the negative control, $N$. meningitidis B16B6, which does not produce any siderophores. ${ }^{28}$

\section{Expression of Lf and Tf receptors}

The results from the $L f$ and $T f$ receptor solid-phase dot-binding assays complemented the plate assays by demonstrating the functional inability of $\boldsymbol{H}$. ducreyi to use $\mathrm{hLf}$ and $\mathrm{hTf}$ as the sole exogenous iron source. No receptor activity was detected in whole-cell and OMP preparations of $\boldsymbol{H}$. ducreyi under iron-limiting conditions that permitted the expression of such receptor activity in $N$. meningitidis B16B6.

\section{OMP profiles}

The OMP profiles of $H$. ducreyi 35000 and $N$. meningitidis B16B6 grown under iron-replete and ironlimited conditions are shown in fig. 2. Comparison of

\section{$\begin{array}{llllllll}a & b & c & d & e & f & g & h\end{array}$}

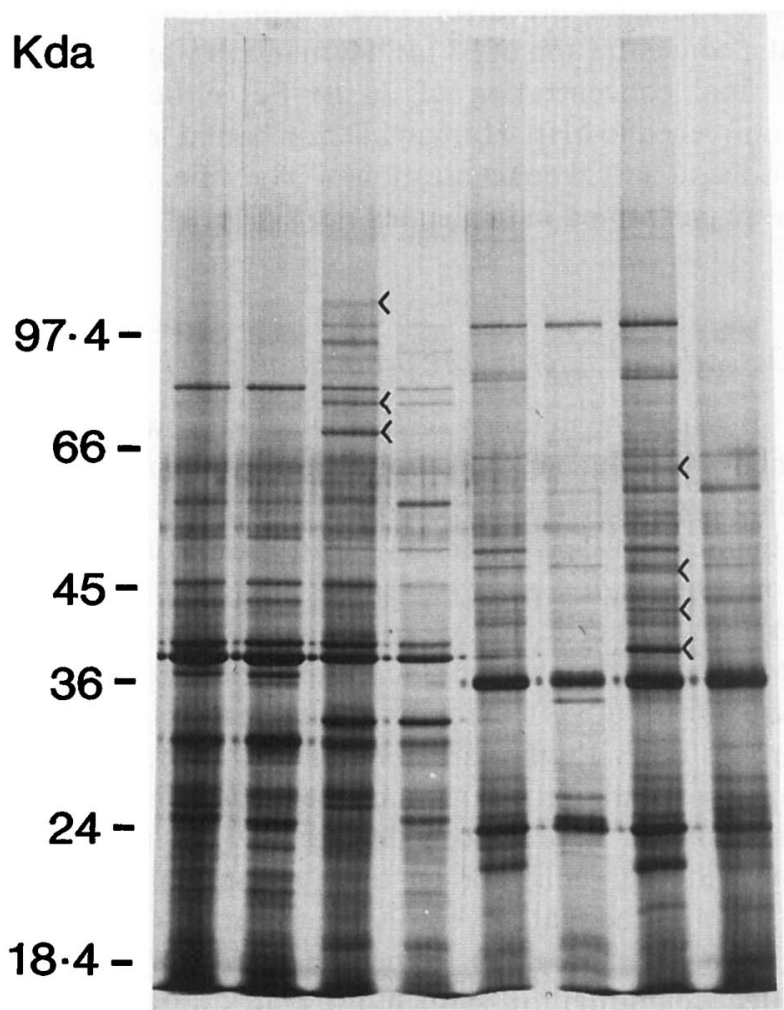

Fig. 2. Silver stained OMP profiles from gradient (8-12\%) SDSPAGE of $N$. meningitidis B16B6 (lanes a-d) and $H$. ducreyi 35000 (e-h) grown under iron-limited and iron-replete conditions. Mol.-wt markers are shown. Lanes $a$ and $e$, cells grown on $\mathrm{CA} ; b$ and $f$, cells grown under haemin-limiting conditions (DM with $38 \mu \mathrm{M}$ haemin); c and $\mathbf{g}$, cells grown under haemin- and iron-deficient conditions (DM with $38 \mu \mathrm{M}$ haemin plus $200 \mu \mathrm{M}$ EDDA); $d$ and $h$, cells grown under haemin-rich conditions (DM with $200 \mu \mathrm{M}$ haemin plus $200 \mu \mathrm{M}$ EDDA). Iron-regulated OMPs are indicated by arrow-heads $(<)$. 
$N$. meningitidis $\mathrm{B} 16 \mathrm{~B} 6$ samples from cells grown under iron-rich (lanes a and d) and iron-limited (lane c) conditions clearly shows three previously described ${ }^{7}$ iron-regulated OMPs of 71,100 and $69 \mathrm{Kda}$. The last two polypeptides correspond to the reported $\mathrm{M}_{\mathrm{r}}$ of the meningococcal Tf receptor. ${ }^{7}$ An identical OMP pattern was observed in membranes prepared conventionally from cultures grown in BHI broth rendered iron-limited. Under similar conditions, four OMPs of $65,50,45 \cdot 5$ and $40 \cdot 5 \mathrm{Kda}$ were detected in preparations from $H$. ducreyi 35000 . The appearance or enhanced expression of these proteins only under iron- and haem-deficient conditions in which haemin served as the sole source of required iron (fig. 2, lane g), but not under haem-restrictive conditions (fig. 2, lane f), and their absence from OMP preparations from cells grown in haem-rich conditions (fig. 2, lanes e and h) indicate that they represent iron-repressible OMPs. In contrast to $N$. meningitidis B16B6, no iron-regulated polypeptides of 69 or $100 \mathrm{Kda}$ were present in OMP preparations from $H$. ducreyi 35000 .

\section{Haemolysin assay}

All $H$. ducreyi strains produced $\beta$-haemolysis. Although no qualitative differences were noted between stab and surface cultures or between ironreplete and iron-limited cultures, there were minor interstrain differences in the degree of haemolysis. The putative haemolysin did not demonstrate species specificity; equivalent haemolysis was produced with sRBC and hRBC. There was no haemolysis under anaerobic conditions.

\section{Discussion}

The natural sources of iron for $H$. ducreyi are unknown. This study indicates that haem can supply the necessary iron to support the growth of $\boldsymbol{H}$. ducreyi. The pronounced partiality for haem is further exemplified by the ability of serum carrier protein complexes of haem or haemoglobin to provide the requisite iron for growth. Such a characteristic is shared by $H$. influenzae. ${ }^{29}$ In contrast, neither $N$. gonorrhoeae nor $N$. meningitidis are capable of extracting haem iron bound to hSA. ${ }^{30}$

However, because of its intrinsic limitation in providing only qualitative data, the plate bioassay method was not suitable for distinguishing minimal quantitative differences in growth stimulation amongst the various haem-containing compounds. Such differences in growth kinetics would be valuable in the optimal formulation of media constituents for primary isolation of $\boldsymbol{H}$. ducreyi.

Most haem proteins reside intracellularly. Although their physiological relevance remains to be determined, the production of a haemolysin, as demonstrated in this study and previously, ${ }^{31}$ and exotoxins ${ }^{32}$ would facilitate access to these iron compounds.
In contrast to the other haem proteins, the inability of cytochrome $\mathrm{C}_{111}$ to promote growth could be explained by the relative inaccessibility of its porphyrin ring. This would be expected because of the covalent binding of the haem prosthetic group to its constituent protein coupled with the reduced surface exposure of haem in cytochrome $\mathrm{C}_{111} \cdot{ }^{33,34}$

The inability of the non-haem compounds to serve as iron sources was not unexpected. Because $H$. ducreyi is haem-dependent, the observed limitation of growth in the presence of non-haem iron compounds may be a reflection of haem restriction rather than of iron deprivation. Since the specific defect(s) in the haem biosynthetic pathway of $\boldsymbol{H}$. ducreyi is not known,, 10 the provision of the immediate haem precursor protoporphyrin IX (PPIX), in the presence or absence of a specific non-haem iron source, was intended to surmount this problem of interpretation. However, the failure of the apoprotein form of haem, PPIX, alone to abrogate the haem dependency of $H$. ducreyi, indicates that the organism cannot assimilate PPIX or lacks the enzyme ferrocatalase that catalyses the insertion of iron into the porphyrin ring, or lacks both abilities. Thus, although conventional iron-uptake and growth studies would discriminate between haem and iron deprivation and would enable determination of whether non-haem iron compounds can serve as iron sources, the inability to produce undispersed liquid cultures of $H$. ducreyi $i^{13}$ precludes the use of these techniques to address these critical issues. However, it is intriguing to note that the apparent absence of a functional $\mathrm{Tf}$ and $\mathrm{Lf}$ receptor in $H$. ducreyi may explain the inability of these glycoproteins to serve as iron sources.

In contrast, in $\boldsymbol{H}$. influenzae, another obligately haem-requiring bacterium, ${ }^{35}$ haem is only one of several forms of iron that satisfies this organism's iron requirements. ${ }^{29}$ Being nutritionally more versatile, $H$. influenzae can extract iron from diverse sources, including $\mathrm{Tf}^{29,36}$

The absence of siderophore production in $\boldsymbol{H}$. ducreyi prompts several speculations. Firstly, the observation that haem is actively transported as an intact molecule in $H$. influenzae ${ }^{37}$ indicates that the acquisition of iron from haem-containing proteins by $\boldsymbol{H}$. ducreyi may involve interaction with a surface exposed haemspecific receptor. The expression of several ironregulated OMPs by $\boldsymbol{H}$. ducreyi is consistent with this proposal; iron-repressible OMPs in other gramnegative bacteria function as receptors involved in iron uptake. ${ }^{2}$ This contention is supported by observations in $H$. influenzae and $N$. gonorrhoeae, two other specific bacterial pathogens of man. In H.influenzae, similar haem-repressible OMPs have been demonstrated which have been suggested as receptors in the haem acquisition pathway. ${ }^{17,37}$ The gonococcus expresses a differential subset of iron regulated OMPs depending upon the specific iron source used. ${ }^{38}$

Lastly, the exclusion of a siderophore component in the uptake pathway, coupled with the apparent 
absence of functional receptors for $\mathrm{Tf}$ and $\mathrm{Lf}$, indicates that $\boldsymbol{H}$. ducreyi may have developed a unique haemrestrictive iron acquisition pathway.

More extensive biochemical and genetic studies are required to corroborate these conjectures. However, this study indicates that $H$. ducrey $i$ has developed iron acquisition mechanisms that may be unique amongst Haemophilus spp. and it may serve as the prototype

\section{References}

1. Bullen JJ. The significance of iron in infection. Rev Infect Dis 1981; 3: 1127-1138.

2. Weinberg ED. Iron withholding: a defence against infection and neoplasia. Physiol Rev 1984; 64: 65-102.

3. Neilands JB. Microbial envelope proteins related to iron. Annu Rev Microbiol 1982; 36: 285-309.

4. Schryvers AB. Characterization of the human transferrin and lactoferrin receptors in Haemophilus influenzae. Mol Microbiol 1988; 2: 467-472.

5. Schryvers AB. Identification of the transferrin- and lactoferrinbinding proteins in Haemophilus influenzae.JMed Microbiol 1989; 29: 121-130.

6. Lee BC, Bryan LE. Identification and comparative analysis of the lactoferrin and transferrin receptors among clinical isolates of gonococci. J Med Microbiol 1989; 28: 199-204.

7. Schryvers AB, Morris LJ. Identification and characterization of the transferrin receptor from Neisseria meningitidis. Mol Microbiol 1988; 2: 281-288.

8. Morse SA. Chancroid and Haemophilus ducreyi. Clin Microbiol Rev 1989; 2: 137-157.

9. Albritton WL, MacLean IW, Bertram PD, Ronald AR. Haemin requirements in Haemophilus with special reference to $H$ ducreyi. In: Kilian M, Frederiksen W, Biberstein EL (eds) Haemophilus, Pasteurella and Actinobacillus. London, Academic Press. 1981: 75-82.

10. Hammond GW, Lian C-J, Wilt JC, Albritton WL, Ronald AL. Determination of the hemin requirement of Haemophilus ducreyi: evaluation of the porphyrin test and media used in the satellite growth test. J Clin Microbiol 1978; 7: 243-246.

11. Cameron DW, Simonsen JN, D'Costa LJ et al. Female to male transmission of human immunodeficiency virus type $\mathrm{I}$ : risk factors for seroconversion in men. Lancet 1989; ii: 403-407.

12. Schmid GP, Sanders LL, Blount JH, Alexander ER. Chancroid in the United States. Reestablishment of an old disease. JAMA 1987; 258 : 3265-3268.

13. Albritton WL. Biology of Haemophilus ducreyi. Microbiol Rev 1989; 53 : 377-389.

14. Holloway BW, Krishnapillai V, Morgan AF. Chromosoma genetics of Pseudomonas. Microbiol Rev 1979; 43: 73-102.

15. Schwyn B, Neilands JB. Universal chemical assay for the detection and determination of siderophores. Anal Biochem $1987 ; 160: 47-56$.

16. Javid J. Human serum haptoglobins. A brief review. Semin Hematol 1967; 4: 35-52.

17. Stull TL. Protein sources of heme for Haemophilus influenzae. Infect Immun 1987; 55: 148-153.

18. Wejman JC, Hovsepian D, Wall JS, Hainfeld JF, Greer J. Structure of haptoglobin and the haptoglobin-hemoglobin complex by electron microscopy. J Mol Biol 1984; 174: 319-341.

19. Hancock REW, Nikaido H. Outer membranes of gram-negative bacteria. XIX. Isolation from Pseudomonas aeruginosa organism in the understanding of haem and porphyrin physiology.

I thank L. E. Bryan and A. B. Schryvers for critical reading of the manuscript, and $\mathrm{R}$. Brunham for providing the $H$. ducrey strains. This study was supported by an Alberta Heritage Foundation for Medical Research Clinical Fellowship and by an ICI Pharma/ Canadian Infectious Disease Society Young Investigator's Award.

PAO1 and use in reconstitution and definition of the permeability barrier. J Bacteriol $1978 ; 136$ : 381-390.

20. Godfrey AJ, Hatletid L, Bryan LE. Correlation between lipopolysaccharide structure and permeability resistance in $\beta$-lactam-resistant Pseudomonas aeruginosa. Antimicrob Agents Chemother 1984; 26: 181-186.

21. Lowry OH, Rosebrough NJ, Farr AL, Randall RJ. Protein measurement with the folin phenol reagent. J Biol Chem 1951; 193: 265-275.

22. Laemmli UK. Cleavage of structural proteins during the assembly of the head of bacteriophage $\mathrm{T}_{4}$. Nature 1970 ; 227: 680-685.

23. Oakley BR, Kirsch DR, Morris NR. A simplified ultrasensitive silver stain for detecting proteins in polyacrylamide gels. Anal Biochem 1980; 105: 361-363.

24. Palumbo G, Tecce MF. A four- to sixfold enhancement in sensitivity for detecting trace proteins in dye or silve stained polyacrylamide gels. Anal Biochem $1983 ; 134$ : 254 258

25. Moore RW, Welton AF, Aust SD. Detection of hemo-proteins in SDS-polyacrylamide gels. Methods Enzymol 1978; 52 : 324-331.

26. Cox CD, Adams P. Siderophore activity of pyoverdin for Pseudomonas aeruginosa. Infect Imun 1985; 48: 130-138.

27. Cox $\mathrm{CD}$, Graham $\mathbf{R}$. Isolation of an iron-binding compound from Pseudomonas aeruginosa. J Bacteriol 1979; 137: 357 364.

28. Archibald FS, DeVoe IW. Removal of iron from human transferrin by Neisseria meningiditis. FEMS Microbiol Let $1979 ; 6: 159-162$

29. Pidcock KA, Wooten JA, Daley BA, Stull TL. Iron acquisition by Haemophilus influenzae. Infect Immun 1988; 56: 721725

30. Dyer DW, West EP, Sparling PF. Effects of serum carrier proteins on the growth of pathogenic Neisseriae with hemebound iron. Infect Immun 1987; 55: 2171-2175.

31. Oberhofer TR, Black AE. Isolation and cultivation of Haemophilus ducreyi. J Clin Microbiol 1982; 15: 625-629.

32. Baine W, Joslin S. Washington DC, American Society for Microbiology. Abstracts of the Annual Meeting, 1988 B34: 35 .

33. Perutz MF. Regulation of oxygen affinity of hemoglobin Influence of structure of the globin on the heme iron. Annu Rev Biochem 1979; 48: 327-386.

34. Salemme FR. Structure and function of cytochromes C. Annu Rev Biochem 1977; 46: 299-329.

35. White DC, Granick S. Hemin biosynthesis in Haemophilus influenzae. J Bacteriol 1963; 85: 842-850.

36. Herrington DA, Sparling PF. Haemophilus influenzae can use human transferrin as a sole source for required iron. Infect Immun 1985; 48: 248-251.

37. Coulton JW, Pang JCS. Transport of hemin by Haemophilus influenzae type-b. Curr Microbiol 1983; 9: 93-98.

38. West SEH, Sparling PF. Response of Neisseria gonorrhoeae to iron limitation: Alterations in expression of membrane proteins without apparent siderophore production. Infect Immun $1985 ; 47$ : 388-394. 